\title{
Essential oil composition and antioxidant activity of Marrubium vulgare L. growing wild in Eastern Algeria
}

\author{
Abderazak Abadi ${ }^{1}$, Aicha Hassani ${ }^{2, *}$ \\ ${ }^{1}$ Laboratoire de Molécules Bio-active et Valorisation de la Biomasse, École Normale Supérieure, \\ BP 92, Kouba-Algiers, Algeria \\ ${ }^{2}$ Laboratoire de Chromatographie, Faculté de Chimie, USTHB, Algiers, Algeria \\ *E-mail address: ryadabadi@gmail.com
}

\begin{abstract}
In previous work [1], the essential oil of the aerial parts of Marrubium vulgare L. obtained by hydrodistillation was analysed by gas chromatography coupled to mass spectrometry (GC-MS) in order to determine their chemical composition. Fifty (50) components in the oil of M. vulgare were identified. The results demonstrated that the major components of the essential oil were: 4,8,12,16Tetramethyl heptadecan-4-olid (16.97\%), Germacrene D-4-ol (9.61 \%), $\alpha$ - pinéne (9.37\%), Phytol (4.87\%), Dehydro-sabina ketone (4.12\%), Piperitone (3.27\%), $\delta$-Cadinene (3.13\%), 1-Octen-3-ol $(2.35 \%)$ and Benzaldehyde $(2.31 \%)$. In this study, the antioxidant properties of essential oil were examined. The results showed that this oil can be considered an effective source of antioxidants of natural origin. This is the first report on chemical composition of $M$. vulgare essential oil cultivated in Algeria and the original study on the antioxidant activity of $M$. vulgare essential oil. The antioxidant activity was investigated with one method: 2,2-diphenyl-1-picrylhydrazyl (DPPH) radical scavenging method.
\end{abstract}

Keywords: Marrubium vulgare; Lamiaceae; Essential oil composition; GC; GC/MS; antioxidant

\section{INTRODUCTION}

In recent years, essential oils of plants and their other products from secondary metabolism have been in high demand from the manufacturers of foods flavoring, fragrance, cosmetics, and pharmaceutical industries due to the growing interest of consumers in ingredients from natural sources. Many plants have been used for different purposes, such as food, drugs and perfumery. They have been screened for their potential uses as alternative remedies for the treatment of many infections and preservation of foods from the toxic effects of oxidants [2].

Lamiaceae is composed of more than 240 genera, most of them are highly aromatic due to the presence of external glandular structures, namely peltate and capitate trichomes that produce essential oils. According to Lawrence [3], it is possible to distinguish between the Lamiaceae oil-rich and oil-poor species. The latter being characterized by hydrocarbon-rich oils, such as germacrene $\mathrm{D}, \beta$-caryophyllene, (E)- $\beta$-farnesene, $\delta$-cadinene and $\alpha$-humulene, 
among others. The Marrubium genus is represented by about 30 species [4]. Considered oilpoor species [3], little is known about their essential oils since more importance has been given to their maceration extract, which is consisted of the known and dominant active component marrubiin [5]. Marrubium vulgare, commonly known as horehound or boarhound, is native in Europe, Western Asia and North Africa, and is cultivated worldwide as a source for food flavoring and for medicinal purposes [6,7]. The name "marrubium" refers to the bitter taste of the herb and "hoar" to the white pubescence covering the plant [8].

Under Polish climatic conditions, Marrubium vulgare L. is aperennial plant. Medicinal properties of horehound have been long known and the origin of its use goes back to ancient Egypt. The medicinal raw material is the herb of horehound (Marrubi herba) [9]. The herb consists of whole or crushed flowering aerial parts of Marrubium vulgare L [10], and it shows multiple effects on human organism [11-13]. The essential oil of Marrubium vulgare L. has a relaxant and expectorant effect as well as a vasodilator [14].

In Algeria, Marrubium vulgare is used in folk medicine to cure several diseases of the digestive tract, such as diarrhoea, as well as diabetes, rheumatism, cold and respiratory pains $[15,16]$. Pursuing our studies on the Algerian flora, this work reports the morphology and distribution of the glandular trichomes of M. vulgare growing spontaneously in Algeria, and the composition of its oil during the flowering and vegetative phases.

Synthetic antioxidants are widely used to retard undesirable changes as a result of oxidation in many foods. Excessively, oxidized fats and oils are not suitable for nutritive purposes. Because the oxidation products of oils have toxic effects, many synthetic substances such as propylgallate and citric acid are commonly used in lipids to prevent oxidation. Recently, these synthetic substances have been shown to cause effects, such as enlarging the liver size and increasing the microsomal enzyme activity.

The use of butylated hydroxyanisole (BHA) and butylated hydroxytoluene (BHT) have been restricted in food because of its carcinogenic effect. Therefore, the search for new natural antioxidant sources has been greatly intensified. In this field, plant originated antioxidants have been widely used in oils or lipid containing foods in order to prevent oxidative deterioration. The main purpose of this study was to investigate the chemical composition of $M$. vulgare essential oil and to determine its antioxidant activity by Scavenging of DPPH (1,1- diphenyl-2-picrylhydrazyl) test.

\section{EXPERIMENTAL}

\section{1. Chemicals, reagents and plant material}

Plant materials (aerial parts) of $M$. vulgare L. were grown in the zone of Nigrine district of El-Ater in the wilaya of Tebessa, north east of Algeria. The whole plants were collected during the period of May to June 2009.

\section{2. Distillation of essential oil}

The samples were dried in the shade in natural air far from moisture and all pollutants for a fortnight in the room temperature.

$100 \mathrm{~g}$ of ground rosemary were submitted to water distillation for $4 \mathrm{~h}$ using a Clevenger apparatus. The distilled essential oils were dried over anhydrous sodium sulfate, filtered and stored at $4{ }^{\circ} \mathrm{C}$. 


\section{3. Gas chromatography}

The gas chromatographic analyzes were performed using a Hewlett Packard 6890 chromatograph equipped with a nonpolar column HP5MS $(30 \times 0.25 \mathrm{~mm}$ d.i. , Film thickness 0.25 microns) and a flame ionization detector. The procedures conditions were as follow: carrier gas: nitrogen, flow rate $0.8 \mathrm{ml} / \mathrm{min}$, injector temperature: $250{ }^{\circ} \mathrm{C}$, detectors temperature: $300{ }^{\circ} \mathrm{C}$, temperature program: from 60 to 250 at $2{ }^{\circ} \mathrm{C} / \mathrm{min}$, with two levels: 8 minutes at $60{ }^{\circ} \mathrm{C}$ and $15 \mathrm{~min}$ at $280{ }^{\circ} \mathrm{C}$, injection of $0.4 \mu \mathrm{l}$ of pure essential oil and $1 \mu \mathrm{l}$ of absolute mode: mode split 1: 20 .

In order to determine retentions indices (RI) a series of n-alkanes (C5-C28) mixture was analysed under the same operative conditions on HP-5 columns and the sample indices were calculated following Van den Dool and Kratz [17].

\section{4. Gas chromatography and mass spectrometry (GC/MS) analysis conditions}

The essential oils were analyzed on an apparatus of gas chromatography coupled to mass spectrometry brand Hewlet Packard 5973 A, equipped with an a polar capillary column (HP5MS, $30 \mathrm{~m} \times 0.25 \mathrm{~mm}$, phase thickness: $0.25 \mu \mathrm{m}$ ). the detection mode: electronic impact, ionization current: $70 \mathrm{eV}$, carrier gas: helium, flow rate: $0.7 \mathrm{ml} / \mathrm{mn}$, the source pressure: 10-7 mbar, interface temperature: $280{ }^{\circ} \mathrm{C}$, injection: $250{ }^{\circ} \mathrm{C}$, the programming of the oven: $2{ }^{\circ} \mathrm{C} /$ min from $60{ }^{\circ} \mathrm{C}$ to $280{ }^{\circ} \mathrm{C}$, with isothermal: $8 \mathrm{~min}$ at $60^{\circ} \mathrm{C}$ and 15 minutes at $280{ }^{\circ} \mathrm{C} 0.1$ to 0.2 $\mu \mathrm{l}$ of pure essential oil and $1 \mu \mathrm{l}$ absolutely were injected in split mode 1: 20 .

The identification of the essential oil constituents was based on a comparison of their retention times to $n$-alkanes, compared to published data and spectra of authentic compounds using their mass spectra compared to the Wiley version 7.0 library [18-20]. as well as by comparison of the fragmentation patterns of mass spectra with those reported in the literature (Adams, 2007). The chromatographic conditions were identical to those used for GC analysis.

\subsection{Antioxidant activity}

The ability of $M$. vulgare oil to scavenge free radicals were assayed with the use of a synthetic free radical compound, 1,1-diphenyl-2-picrylhydrazyl (DPPH), according to the method employed by Bersuder [20], a volume of $500 \mu \mathrm{l}$ of each sample was mixed with 50 $\mathrm{lml}$ of ethanol and $(0.02 \%, \mathrm{w} / \mathrm{v})$ of DPPH in $99.5 \%$ ethanol. The mixture was shaken vigorously and incubated in the dark. After $30 \mathrm{~min}$, the absorbance was measured at $517 \mathrm{~nm}$ using a spectrophotometer. The DPPH radical-scavenging activity was calculated as follows:

$$
\text { Radical-scavenging activity }=\left[\left(A_{\text {blank }}-A_{\text {sample }}\right) / A_{\text {blank }}\right] \times 100
$$

where, $A_{\text {blank }}$ and $A_{\text {sample }}$ are the absorbance of the control (blank) and the sample, respectively.

The $\mathrm{IC}_{50}$ value is defined as the amount of antioxidant necessary to inhibit DPPH radical formation by $50 \%$.

The synthetic antioxidant reagent BHT was used as a positive control. The values are presented as the means of triplicate analysis. 


\section{RESULTS AND DISCUSSION}

\section{1. Chemical composition}

The study showed that the essential oil content in the dry herb of Marrubium vulgare L. was on average $0.05 \%$ [21].

Figure 1 shows the peaks of GC-MS spectrum. The search analysis in the digital library. The percentages and the retention indices of the identified components are listed in Table 1 in the order of their elution on the HP-5MS column. GC-MS analysis of M.vulgare essential oil led to the identification of fifty (50) compounds, accounting for $82.42 \%$ of the total oil. The yield of essential oil obtained by hydrodistillation from aerial part of plant was $0.04 \%$.

Table 1 illustrates also the nine components with a supremacy of three major compononents: 4,8,12,16-Tetramethyl heptadecan-4-olid (16.97\%), Germacrene D-4-ol (9.61 $\%), \alpha$ - pinene $(9.37 \%)$. They represnt about $36 \%$ of $56 \%$ and shows the different chemical groups with a dominance of other compounds with $41.64 \%$ of the total rate of volatil oil, followed by Oxygenated sesquiterpene with a lower rate $(13.17 \%)$ and, Monoterpene hydrocarbon (12.61\%) Oxygenated monoterpene (9.46 \%), Sesquiterpene hydrocarbon (5.58 $\%$ ) respectively.

\section{2. Antioxidant activity}

Relatively stable organic radical DPPH has been widely used in the determination of the antioxidant activity of the essential oil. DPPH radical decreased in the presence of a hydrogen donor, that is, a free radical-scavenging antioxidant.

In the DPPH-test, the ability of the essential oil to act as the donor of hydrogen atoms or electrons in the transformation of DPPH into its reduced form DPPH-Hwas measured spectrophotometrically. Assessed samples were able to reduce the stable violet DPPH radical to the yellow DPPH-H, reaching $50 \%$ of reduction with IC50 values. Lower IC50 value indicates higher antioxidant activity.

The results represented in Figure 2 of the DPPH radical scavenging activities (\% inhibition) of various concentrations of $M$. vulgare oil showed a concentration dependent activity profile. As shown, it is clear that as the concentration increased, the scavenging effect also increased with inhibitory activity observed as was in the case of $M$. vulgare oil, reaching as high as 254 at $1000 \mu \mathrm{g} / \mathrm{ml}$.

This value is too close to the activity potentials of synthetic antioxidants BHT ( $35 \mu \mathrm{g} / \mathrm{ml}$ ) at the same concentration. The amount of the essential oil needed for $50 \%$ inhibition of free radical activity is expressed by IC50 (the concentration reducing $50 \%$ of DPPH).

The lower the IC50 value is, the greater the free radical-scavenging activity. The results depicted in Figure 3 indicate that $M$. vulgare essential oil exhibited an $\mathrm{IC}_{50}$ value of 153.84 $\mu \mathrm{g} / \mathrm{ml}$, which is about 2 times higher than the synthetic antioxidant (BHT).

The efficiency of an antioxidant component to reduce DPPH essentially depends on its hydrogen donating ability, which is directly related to the less content of phenolic hydroxyl moieties. 


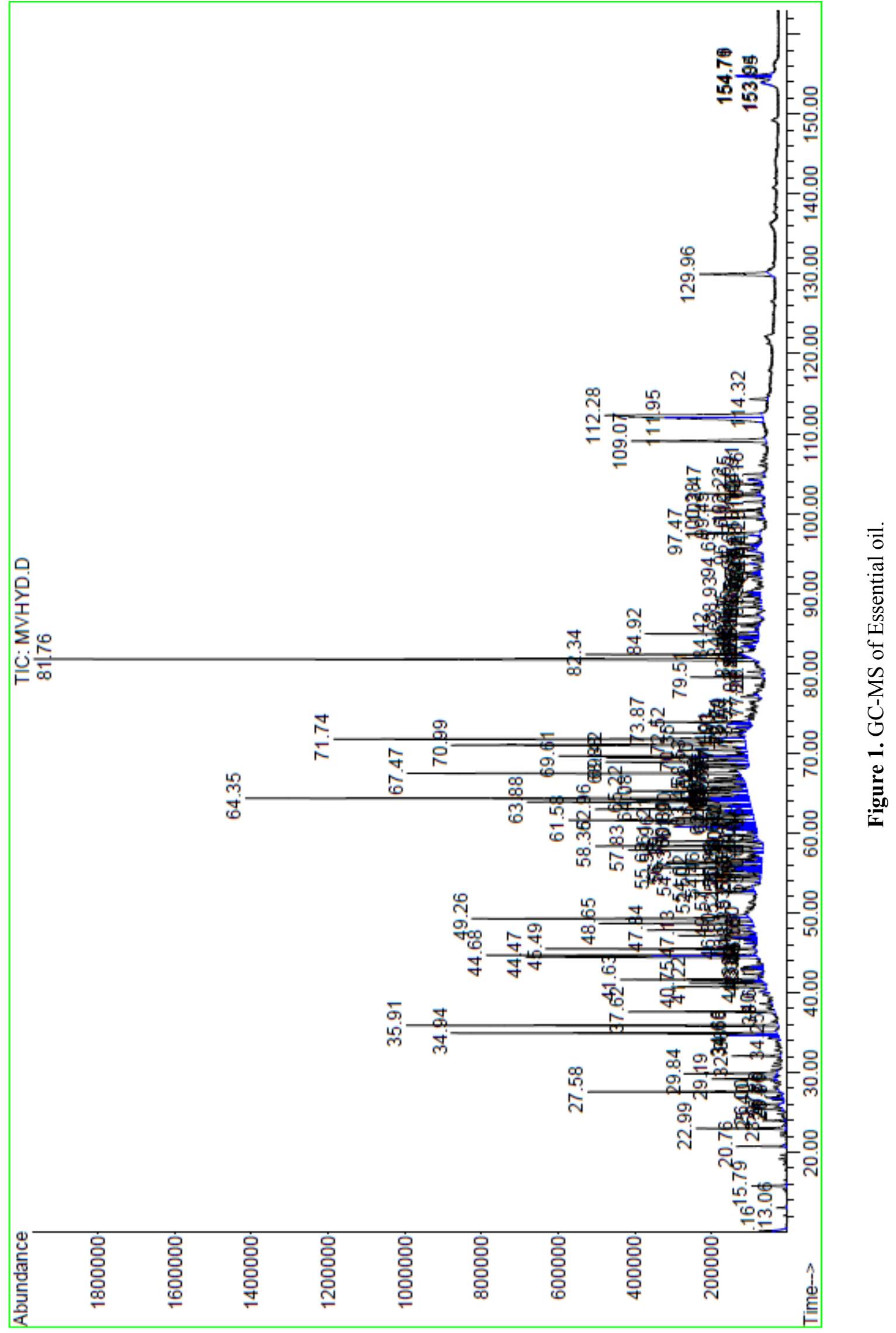


Table 1. Chemical composition, retention indices (IR) and percentage composition of the $M$. vulgare essential oil.

\begin{tabular}{|c|c|c|c|c|}
\hline $\mathbf{N}^{\circ}$ & IR & Compound & $\%$ & Identification \\
\hline 1 & 823 & Trans -2-Hexanal & 0.75 & GC,GC/MS \\
\hline 2 & 903 & Heptanal & 0.1 & $\mathrm{GC}$ \\
\hline 3 & 906 & Santolina triene* & 0.71 & $\mathrm{GC}, \mathrm{GC} / \mathrm{MS}$ \\
\hline 4 & 937 & $\alpha$-pinene & 9.37 & $\mathrm{GC}, \mathrm{GC} / \mathrm{MS}$ \\
\hline 5 & 946 & Camphene & 0.51 & GC,GC/MS \\
\hline 6 & 953 & Benzaldehyde & 2.31 & $\mathrm{GC}$ \\
\hline 7 & 962 & Sabinene & 0.37 & $\mathrm{GC}$ \\
\hline 8 & 983 & 1-Octen-3-ol & 2.35 & $\mathrm{GC}$ \\
\hline 9 & 990 & Myrecene & 0.47 & $\mathrm{GC}, \mathrm{GC} / \mathrm{MS}$ \\
\hline 10 & 995 & Octanol-3 & 0.64 & GC \\
\hline 11 & 1000 & Dichlorobenzene $<1,>*$ & 0.72 & $\mathrm{GC}, \mathrm{GC} / \mathrm{MS}$ \\
\hline 12 & 1022 & p-Cymene & 0.63 & $\mathrm{GC}, \mathrm{GC} / \mathrm{MS}$ \\
\hline 13 & 1029 & 1-8-cineole & 0.1 & GC \\
\hline 14 & 1038 & cis-Ocimene & 0.2 & $\mathrm{GC}$ \\
\hline 15 & 1055 & $\gamma$-Terpinene & 0.85 & GC,GC/MS \\
\hline 16 & 1113 & ß-Thujone & 0.81 & $\mathrm{GC}, \mathrm{GC} / \mathrm{MS}$ \\
\hline 17 & 1117 & Dehydro-sabina ketone* & 4.12 & $\mathrm{GC}, \mathrm{GC} / \mathrm{MS}$ \\
\hline 18 & 1122 & Camphor & 0.83 & $\mathrm{GC}, \mathrm{GC} / \mathrm{MS}$ \\
\hline 19 & 1219 & Carvone & 0.89 & $\mathrm{GC}$ \\
\hline 20 & 1224 & Piperitone & 3.27 & GC \\
\hline 21 & 1239 & Neral & 0.27 & $\mathrm{GC}, \mathrm{GC} / \mathrm{MS}$ \\
\hline 22 & 1250 & Geraniol & 0.92 & GC \\
\hline 23 & 1261 & Anethole $<\mathrm{E}>$ & 0.47 & $\mathrm{GC}, \mathrm{GC} / \mathrm{MS}$ \\
\hline 24 & 1275 & Geranial & 0.78 & $\mathrm{GC}$ \\
\hline 25 & 1282 & Thymol & 0.17 & $\mathrm{GC}, \mathrm{GC} / \mathrm{MS}$ \\
\hline 26 & 1284 & 2-Undecanone & 0.98 & $\mathrm{GC}, \mathrm{GC} / \mathrm{MS}$ \\
\hline 27 & 1291 & Cymen-7-ol<p $>*$ & 0.95 & GC \\
\hline 28 & 1467 & $\alpha$-Humulene & 0.12 & GC \\
\hline 29 & 1481 & Germacrene D & 0.88 & GC \\
\hline 30 & 1491 & ß-Guaiene & 0.23 & $\mathrm{GC}, \mathrm{GC} / \mathrm{MS}$ \\
\hline 31 & 1501 & $\alpha$ - Farnesene & 0.23 & $\mathrm{GC}, \mathrm{GC} / \mathrm{MS}$ \\
\hline 32 & 1505 & $\gamma$-Cadinene & 0.44 & $\mathrm{GC}, \mathrm{GC} / \mathrm{MS}$ \\
\hline 33 & 1510 & Trans -calamenene & 0.21 & $\mathrm{GC}$ \\
\hline 34 & 1513 & $\delta$ - Cadinene & 3.13 & $\mathrm{GC}, \mathrm{GC} / \mathrm{MS}$ \\
\hline 35 & 1521 & Trans-Cadina-1-4-diene* & 0.21 & $\mathrm{GC}, \mathrm{GC} / \mathrm{MS}$ \\
\hline 36 & 1529 & $\alpha$ - calacorene & 0.73 & GC \\
\hline 37 & 1538 & Germacrene D-4-ol & 9.61 & GC,GC/MS \\
\hline 38 & 1566 & Spathulenol & 0.87 & $\mathrm{GC}$ \\
\hline 39 & 1574 & Salvial-4(14)-en-1-one* & 0.96 & GC,GC/MS \\
\hline 40 & 1579 & ß- oplopenone & 0.63 & GC,GC/MS \\
\hline 41 & 1845 & trans-trans-Farnesyl acetate* & 0.8 & GC \\
\hline 42 & 1862 & cis-cis-Farnesyl acetone* & 0.98 & $\mathrm{GC}, \mathrm{GC} / \mathrm{MS}$ \\
\hline 43 & 1876 & Trans-cis-Farnesyl acetone* & 0.77 & $\mathrm{GC}, \mathrm{GC} / \mathrm{MS}$ \\
\hline 44 & 1895 & Nonadecane & 0.53 & $\mathrm{GC}, \mathrm{GC} / \mathrm{MS}$ \\
\hline 45 & 1921 & Phytol & 4.87 & $\mathrm{GC}, \mathrm{GC} / \mathrm{MS}$ \\
\hline 46 & 2102 & n-Heneicosane* & 0.8 & $\mathrm{GC}, \mathrm{GC} / \mathrm{MS}$ \\
\hline 47 & 2135 & Linoleic acid* & 1.0 & GC,GC/MS \\
\hline 48 & 2210 & Sclareol* & 0.81 & GC,GC/MS \\
\hline 49 & 2303 & Tricosane* & 0.96 & $\mathrm{GC}, \mathrm{GC} / \mathrm{MS}$ \\
\hline \multirow[t]{8}{*}{50} & 2327 & $\begin{array}{l}\text { 4,8,12,16Tetramethyl } \\
\text { heptadecan-4-olid* }\end{array}$ & 16.97 & $\mathrm{GC}, \mathrm{GC} / \mathrm{MS}$ \\
\hline & Total & & 82.46 & \\
\hline & & Grouped Compounds & & \\
\hline & & Monoterpene hydrocarbon & 12.61 & \\
\hline & & Oxygenated monoterpene & 9.46 & \\
\hline & & Sesquiterpene hydrocarbon & 5.58 & \\
\hline & & Oxygenated sesquiterpene & 13.17 & \\
\hline & & Others Compounds & 41.64 & \\
\hline
\end{tabular}




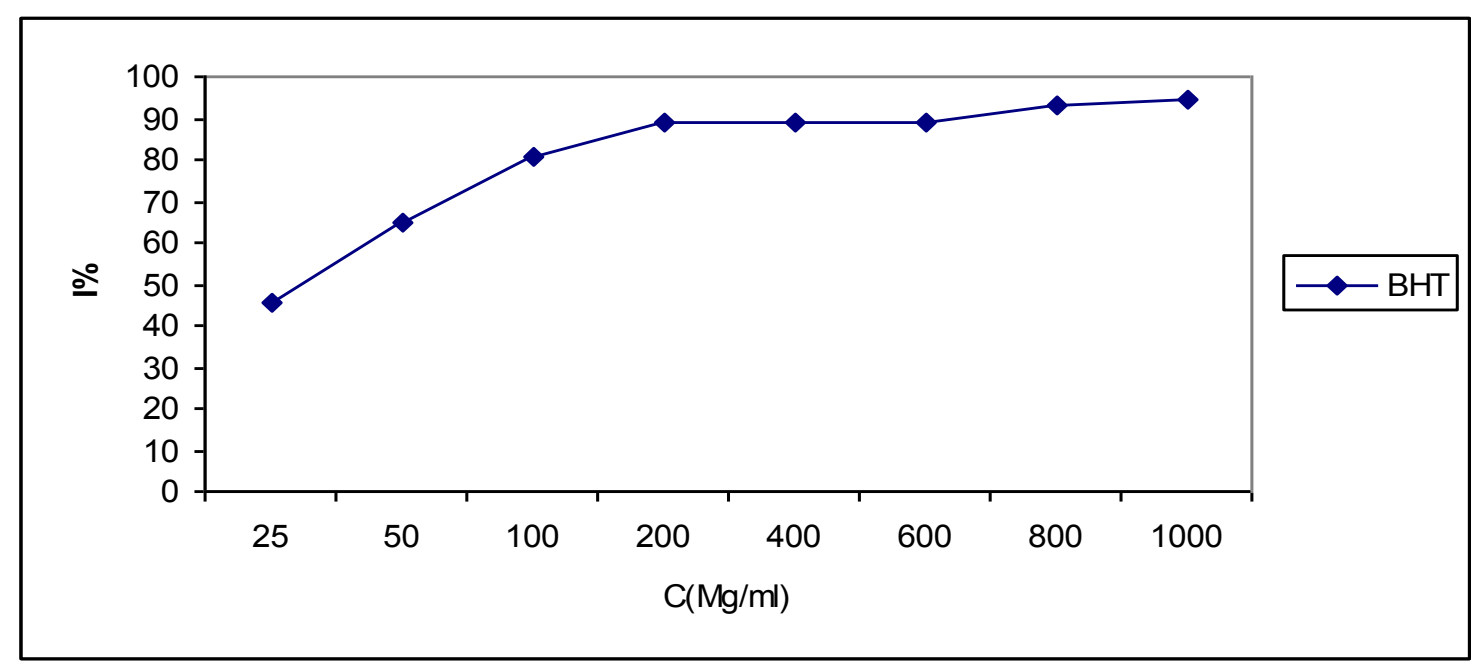

Figure 2. The synthetic antioxidant BHT.

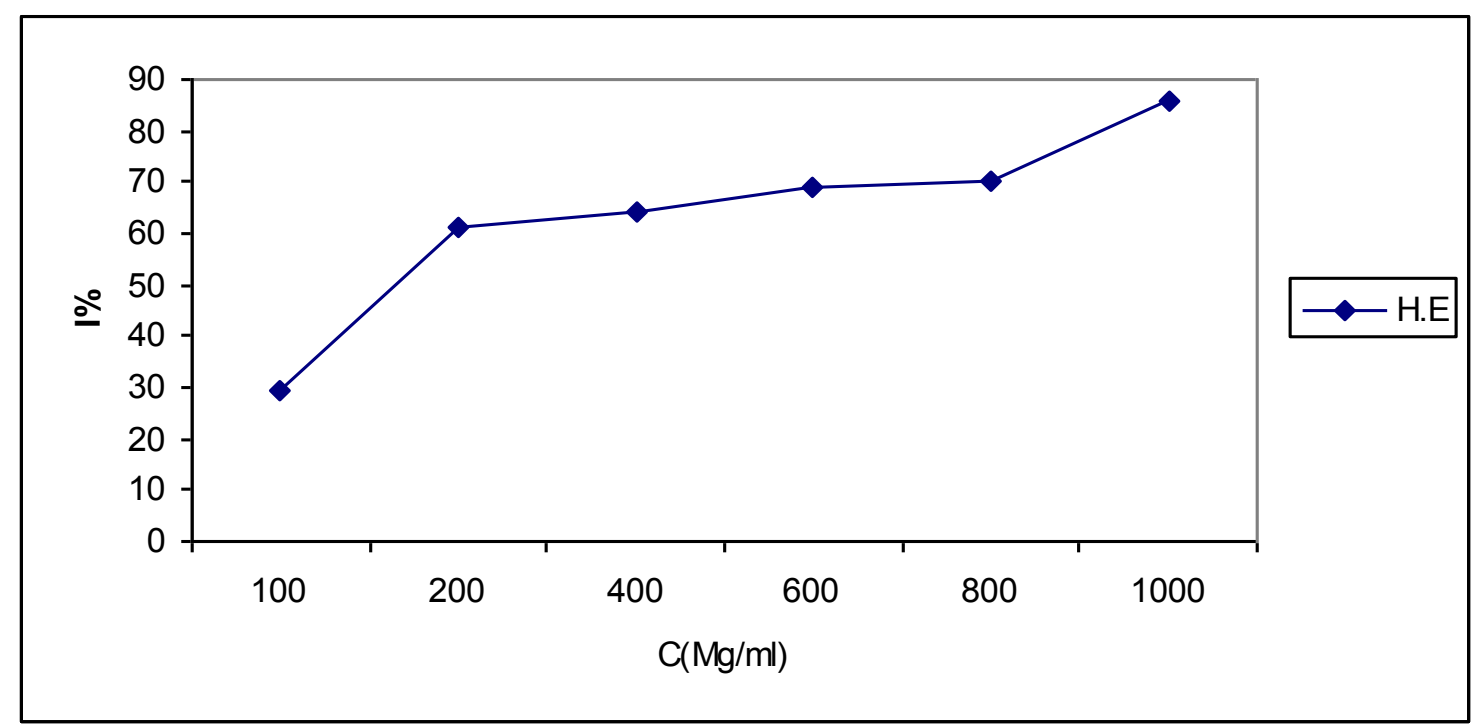

Figure 3. Antioxidant activity of M. vulgare essential oil.

\section{CONCLUSION}

Essential oil of $M$. vulgare from Algeria had significant differences in the chemical composition as compared to the same essential oil from other country, which can be attributed to several factors.

The results demonstrated that the major components of the essential oil were: 4,8,12,16-Tetramethyl heptadecan-4-olid (16.97\%), Germacrene D-4-ol (9.61\%), $\alpha$ - pinéne (9.37 \%), Phytol (4.87\%), Dehydro-sabina ketone (4.12\%), Piperitone $(3.27 \%), \delta-$ Cadinene $(3.13 \%), 1$-Octen-3-ol $(2.35 \%)$ and Benzaldehyde $(2.31 \%)$. The results showed that this oil can be considered an effective source of antioxidants and enhance the human health as natural antioxidant. 


\section{ACKNOWLEDGMENTS}

Support of the work by the Laboratoire de Molécules Bio-active et Valorisation de la Biomasse, École Normale Supérieure is gratefully acknowledged. We would like to thank Professor Mrs Aicha Hassani, for his help, and Laboratoire de Chromatographie, Faculté de Chimie, USTHB, Algiers, Algeria. For their support.

\section{References}

[1] A. Abadi, A. Hassani, Inter. Lett. Chem. Phys. Astro. 8(3) (2013) 210-214.

[2] Barlow S. M., Hudson B. J. F., (Ed.), Elsevier, Amsterdam 1990, pp. 23.

[3] B. M. Lawrence, Science. Edits., R. M. Harley, T. Reynolds, Royal Botanic Gardens, Kew 1992, pp. 399-436.

[4] M. S .Abu-Asaband, R. D. Cantlno, In: Advances In Lablate Science. Edits. R. M. Harley, T. Reynolds, Royal Botanic Gardens, Kew (1992, pp. 97-112.

[5] V. Schiemper, A. Ribas, M. Nlcolau, V. Cechinel-Fliho, Phytomedecine 3 (1996) 211-216.

[6] W. Letchamo, S. Mukhopadhyay, J. Hortic. ScI. 72(1997) 741-748.

[7] S. Sahpaz, et al., Journal of Ethnopharmacology 79 (2002) 389-392.

[8] J. E.Slmon, A. F. Chadwickand, L. E. Craker, Herbs-anIndexedblbllograptry 1971-1980, Elsevler, Amsterdam 1984, p. 48.

[9] Wolski T., Matosiuk D., Baj T., Ziewiec A., , Postępy Fitoterapii 1 (2007) 39-45.

[10] Polish Pharmacopoeia VIII. PTFarm., Warszawa 2008, pp. 2249-2250.

[11] Bradley P. R., British Herbal Medicine Association 1 (1992) 218-220.

[12] El Bardai S., Wibo M., Hamaide M-Ch., Lyoussi B., Quetn-Leclerq J., Morel N., British Journal of Pharmacology 140 (2003) 1211-1216.

[13] Kohlmünzer S., Farmakognozja, Wydawnictwo Lekarskie PZWL Warszawa, 2007, p. 308.

[14] Wyk B. E., Wink M., Rośliny lecznicze świata, MedPharm Polska, 2008, p. 198.

[15] Rachid Belhattab, Larbi Larous, J. Essent. Oil Res. 18 (2006) 369-373.

[16] Y. Mahmoudi, La thérapeutique par les plantes communes en Algérie. Ed. Palais du livre, Blida(1990).

[17] H. Van den Dool, P. D. Kratz, J. Chromatogr. 11 (1963) 463.

[18] F. Macchioni, P. L. Cioni, G. Flamini, I. Morelli, S. Maccioni, M. Ansaldi, Flavour Frag. J. 18 (2003) 139.

[19] V. Roussis, P. Katerina, V. Constantinos, P. V. Catherine, O. Antonio, J. Essent. Oil Res. 13 (2001) 118.

[20] R. P. Adams, Identification of Essential Oils by Ion Trap Mass Spetroscopy, Allured Publishing Corporation, Carol Stream, IL, USA, 1995.

[21] Zawiślak G., Herba Pol. 55(3) (2009) 63-68. 